\title{
Take it Personally - The Role of Consumers' Perceived Value of Personalization on Cross-Category Use in a Smart Home Ecosystem
}

\author{
Marco Hubert \\ Department of \\ Management \\ Aarhus University \\ $\underline{\text { mah@mgmt.au.dk }}$
}

\author{
Andrea Carugati \\ Department of \\ Management \\ Aarhus University \\ andrea@mgmt.au.dk
}

\author{
Christian Brock \\ Chair of Marketing \\ University of Rostock \\ christian.brock@uni- \\ rostock.de
}

\author{
Børge Obel \\ Department of \\ Management \\ Aarhus University \\ $\underline{\text { bo@icoa.au.dk }}$
}

\begin{abstract}
The establishment of a smart home ecosystem - an assemblage of smart technologies across segments in private households - generates value for both companies and customers. However, the complexity of a smart home ecosystem based on data sharing and personalization as a necessity for value perception also generates tensions between the value created by data sharing and the value of privacy. Therefore, this study, based on a survey of 1049 consumers, investigates the acceptance and use of smart home devices and smart home ecosystems by observing drivers of personalization, trust, privacy components and technology acceptance. The empirical analyses show that especially consumers' perceived value from personalization plays a significant role in smart home ecosystem acceptance. This research offers results for theory development and practical implications by extending existing technology acceptance models to ecosystems and by showing the need for a focus on sophisticated personalized applications within a smart home ecosystem.
\end{abstract}

\section{Introduction}

In the age of the internet of things, the presence of smart devices in everyday life is rapidly growing. This poses new challenges to owners, who need to constantly adjust to the promising but also still unknown new technologies. In addition, organizations have to adjust their products and their relations to other products to provide more value in a smart home ecosystem than they do alone. Both customers and organizations have to deal with and adapt to these transformational digital shifts.

One of the most recent - and economically interesting - areas for smart devices is the smart home
[14]. By smart devices in a smart home, we refer to devices such as bulbs, coffee machines, locks, speakers, cameras, windows or thermostats with embedded information technology (IT) that allows them to (1) be connected into a network; (2) interact autonomously with other similar devices; (3) be controlled by a smart phone or apps; (4) be upgraded; (5) collect data from usage; and (6) display a form of intelligence (understand, react, predict) [14, 28]. Advanced examples could be thermostats that learn the house inhabitants' behavior and adapt the heating to their needs, alarm systems that automatically turn on and off based on the house owners' location, or cameras that automatically recognize a face or a dangerous situation.

For customers and users, this multifaceted assemblage of connected smart technologies across categories (e.g., security, energy management, lighting) - the smart home ecosystem - promises to leverage these characteristics to create a home environment that is adaptive and reactive to its users' needs [13]. For organizations, these devices are revamping the market for home technology in a wave that is forecast to grow constantly over the next five to ten years [14].

In this situation, many existing and new organizations are entering the market for smart home products: first, because these devices can be priced much higher than their "non-smart" counterparts; second, and most important, because these products collect actual customer behavioral data, basically for free. This information can provide insights into customers' use of the device that could have never been collected before. Therefore, various opportunities arise for companies from the integration and implementation of smart products, devices and applications in customers' homes, with stronger customer connection and engagement, interactivity and data collection. 
Nevertheless, from a company-customer perspective, these opportunities and corresponding value generation for both company and customer are mainly related to the concrete and sophisticated setup and installation of the connected smart home ecosystem based on multifaceted technologies from different categories (e.g., home entertainment, security) and different product categories within each category (e.g., security in relation to cameras or doors) [13]. Thus, it is critical to understand consumers' acceptance, use intention and actual use behavior, not only of specific single smart devices, but also of the smart home ecosystem as a whole - with the use of devices across segments. This is crucial, since the smart home ecosystem allows for increased personalization of applications and services and therefore increased customer value and well-being.

However, the importance of increased personalization is complicated by an inherent conflict in the smart home ecosystem. For companies, the value generation of a smart home ecosystem is mainly related to the data acquisition, collection and analysis coming from the use and interaction of customers with the different smart devices and products.

For customers, the value resides instead in striking the right balance between the data shared with the ecosystem and the value of their own privacy. Therefore, for service providers, more data equates to more value, while for customers, data sharing and value have an inverse $\mathrm{U}$-shaped relation (users accept sharing data to receive value, but only up to a certain point, after which the value decreases). Trust becomes a key parameter in mediating this relation [16, 25], since users may be willing to share more data with service providers that they trust more.

Against this backdrop, the assemblage and complexity of a smart home ecosystem based on data sharing and personalized services as a necessity for value generation led us to investigate the relevant aspects of a smart home ecosystem (personalization, privacy and trust sources [31]). Nevertheless, in order to connect with the current literature, we acknowledge and consider specific preconditions and antecedents of acceptance and use behavior from existing research on technology acceptance $[8,19,33,35]$.

In conclusion, this paper and the underlying empirical study want to shed light on trust, privacy and personalization components and their effect on the use of smart home devices across product and service segments in interaction with aspects of technology acceptance and use [2, 34].

\section{Theoretical Background and Hypothesis Development}

This section provides the background for a model of the smart home ecosystem considering that (1) consumers have to accept and use an ecosystem rather than a single device or application; (2) performance typically emerges from the interaction between products, devices and applications; (3) value also depends on the personalization of the ecosystem services to individual use; and (4) privacy and trust in companies play a role in the perceived value of the products and the acceptance of a smart home ecosystem. In the following we provide the theoretical background to these elements and the relative hypotheses.

\subsection{Smart home ecosystem}

A smart or connected home is seen as a residential building (e.g., house or apartment) which implements a mix of different technologies, devices and associated services and applications [28, 37]. These technologies, devices and services are associated with six major categories of a connected home: home entertainment (e.g., smart speakers), control and connectivity (e.g., smart assistants), security (e.g., camera, windows), comfort and lighting (e.g., bulbs), energy management (e.g., thermostats), and smart appliances (e.g., smart fridges) [14].

To increase the comfort, entertainment and security of the user and resident and as a consequence their well-being and use of the technologies, it is crucial to analyze not only consumer perception and behavior with regard to a single technology, but also the intention and use of the smart home ecosystem, which we operationalize as devices that are connected across segments.

Therefore, based on extensive research with regard to technology acceptance and use [19,35], the general intention to use should also be positively connected to the current use of devices across segments. Therefore, we assume that:

H1: There is a positive relation between the intention of a cross-category use of smart home devices and the current cross-category use of smart home devices.

\subsection{Consumers' value for personalization}

Personalization can be defined as the possibility of tailoring products and services according to customers' needs, personal preferences and behavior $[1,6]$. The major benefit of a connected smart home ecosystem is mainly associated with a certain level of personalization, based on the possibility of collecting and analyzing data from devices and its application for interactive and automated services [37]. 
While in the existing literature the intention to use a single technology is often associated with the actual use of this technology, this might be different for a smart home ecosystem. Personalization as a main factor and consumers' perceived value for personalization might play important roles with regard to this relationship. Therefore, we assume that:

H2: The positive relation between the intention of cross-category use of smart home devices and the current cross-category use of smart home devices is mediated by consumers' value for personalization.

\subsection{Trust and disposition to value privacy}

Despite the potential beneficial antecedents of the acceptance and use of a more connected home experience, research is becoming more and more concerned with the use that companies make of behavioral data and derivatives [38]. Personal data usage is a concern for individuals and smart home devices challenge the individual perception of the informal "service for data" contract that characterizes services like social media. Smart home devices skew this balance because individuals often interact with smart devices as they did with regular "non-smart" devices (e.g., switching on a light), without realizing that now the act is recorded somewhere [7]. In this situation, trust is becoming one of the major elements of debate in smart home ecosystems. Especially with regard to smart technology use and acceptance, trust plays a major role as a direct and indirect antecedent of use [31, 37]. Therefore, we assume that:

$\boldsymbol{H 3 a - b :}$ : The positive relation between (a) the intention of cross-category use of smart home devices, (b) consumers'value for personalization and the current cross-category use of smart home devices is mediated by trust in smart home companies.

With regard to privacy issues and concerns, the knowledge about data collection and transfer within a smart home ecosystem in order to generate value for the customer might also trigger security and privacy concerns $[15,22,36]$. Therefore, the disposition to value data privacy might act as an inhibiting factor:

$\mathrm{H} 4 \mathbf{a}-\mathrm{c}$ : There is a negative relation between the disposition to value privacy and (a) the intention of a cross-category use of smart home devices, (b) consumers' value for personalization and (c) the trust in smart home companies.

\subsection{Use of single smart home technologies}

To establish the use of smart home technologies across categories, the habit of using a single technology already [2, 18, 24, 35] often not only leads to repeated use of this specific device, but also to cross-category use of additional technologies [12]. Thus, we hypothesize a spillover effect from the habit of using a single connected home device to the intention to use as well as to the actual use of smart devices across categories. Furthermore, positive experiences might lead to an increased use frequency of a single smart device [17, 18, 35], which becomes a habit and in consequence might affect the value perception of personalized devices and services and trust in associated companies within a smart home ecosystem. Therefore, we assume that:

H5a-d: There is a positive relation between the habit of using a single smart home device and (a) the intention of cross-category use of smart home devices, (b) the current cross-category use of smart home devices, (c) consumers' value for personalization and (d) trust in smart home companies.

\subsection{Drivers of acceptance and use of technology}

With regard to the acceptance and use of technology, information systems research has developed a profound understanding of technology acceptance and use, but mainly with regard to specific single technologies [35]. Nevertheless, antecedents of technology acceptance and use might also play an important role for the acceptance and use of smart devices within a smart home ecosystem. Indeed, especially the unified theory of acceptance and use of technology (UTAUT) antecedents of (a) performance expectancy, (b) effort expectancy, (c) enjoyment, (d) facilitating conditions and (e) price value [35] will have a positive relation to the intention to use smart devices across segments. Therefore, we assume that:

H6a-e: There is a positive relation between (a) performance expectancy, (b) effort expectancy, (c) enjoyment, (d) facilitating conditions, (e) price value and the intention of cross-category use of smart home devices.

Furthermore, before consumers perceive personalization and personalized services associated with a smart home as beneficial, they need to perceive increased performance of a smart home ecosystem versus the performance of a single technology and a low level of effort that they have to invest to set up a smart home ecosystem [13]. Thus, we assume that:

$\boldsymbol{H 7} \boldsymbol{a}-\boldsymbol{b}$ : There is a positive relation between (a) performance expectancy, $(b)$ effort expectancy and consumers' value for personalization. 
Figure 1 summarizes the conceptual framework by implementing a model based on smart home-related antecedents and a model extended with UTAUT.

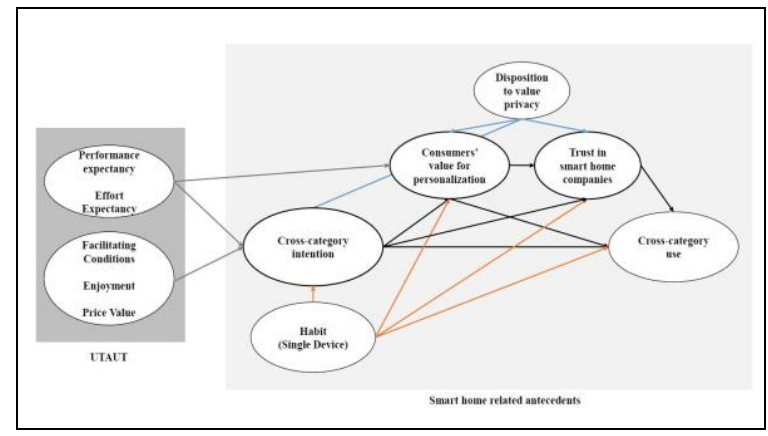

Figure 1. Conceptual framework

\section{Method and Results}

\subsection{Participant selection and questionnaire design}

A total of 3851 participants (2209 female, $M($ age $)=$ $51.92, \mathrm{SD}=16.31$ ) were surveyed through an online panel in three selected European countries: Germany (GER; $\mathrm{n}=1080)$, Denmark (DK; $\mathrm{n}=1478)$ and Norway $(\mathrm{NO} ; \mathrm{n}=1293)$.

In order to obtain only owners and users of smart home devices, three screen-out criteria were applied. First, participants had to be familiar with the introduced concept of a connected/smart home ("We use the term to refer to everyday objects and smart devices that connect to the internet, to each other and with humans; not computers, smartphones, or tablets alone. Connected home represents a whole that is more than the sum of the devices due to interactional experience. Smart devices often connect to apps on mobile devices, allowing users to control them remotely. However, they can also operate autonomously on the basis of their internal state and/or the state of the environment [...]") on a 5-point Likert scale (with $1=$ "not familiar at all" to $5=$ "very familiar"). Participants who were rarely familiar with the concept (with values equal to or lower than 2) were excluded. Second, participants had to own or rent a house or an apartment. Third, participants had to own a smart home device/technology.

Therefore, the final sample consists of 1049 participants (514 female, $M($ age $)=45.73, \mathrm{SD}=15.02$; GER: $\mathrm{n}=334,150$ female, $M($ age $)=44.09, \mathrm{SD}=$ 13.72; DK: $\mathrm{n}=369,191$ female, $M($ age $)=46.38$, SD $=15.30 ;$ NO: $\mathrm{n}=346,173$ female, $M($ age $)=46.60, \mathrm{SD}$ $=15.82$; no missing values).

Within the main questionnaire, participants had to answer questions with regard to (1) the different UTAUT dimensions: (a) performance expectancy (PE,
4 items; "I find the services provided by a connected/smart home device useful", "A connected/smart home device increases my chances of achieving things that are important to me", "A connected/smart home device helps me accomplish things more quickly", "A connected/smart home device increases my productivity"); (b) effort expectancy (EE, 4 items, "Learning how to use a connected/smart home device is easy for me", "My interaction with a connected/smart home device is clear and understandable", "I find a connected/smart home device easy to use", "It is easy for me to become skillful at using a connected/smart home device"); (c) enjoyment (ENJ, 2 items, "When using smart home technology, I primarily want to have fun", "When using smart home technology, I primarily want to relieve boredom"); (d) facilitating conditions (FC, 4 items, "I have the resources necessary to use a connected/smart home", "I have the knowledge necessary to use a connected/smart home", "A connected/smart home is compatible with other technologies I use", "I can get help from others when I have difficulties using a connected/smart home"); and (e) price value (PV, 3 items, "A connected/smart home device is reasonably priced", "A connected/smart home device is a good value for the money", "At the current price, a connected/smart home device provides good value") [12, 35]; (2) their perceived value for personalization (CVP, 3 items, "I value smart home technology that is personalized for the device that I use", "I value smart home technology that is personalized for my usage experience preferences", "I value smart home technology that acquires my personal preferences and personalizes the services and products themselves") The scale originally consisted of six items. However, we have chosen only those three which point to personalized data without limitations (e.g., anonymity). [6]; and (3) their trust in connected/smart home companies (TR, 4 items, "Companies selling smart home technology are: dishonest/honest, unreliable/reliable, untrustworthy/trustworthy, insincere/sincere" [5] and their disposition to value privacy (DVP, 2 items, "Compared to others, I am more sensitive about the way online companies handle my personal data", "To me, it is the most important thing to keep my online privacy") [36] on a 7-point Likert scale (with $1=$ "totally disagree" to 7 = "totally agree").

Concerning the habit of using a specific single smart home device (HA), participants had to answer questions with regard to their usage frequency of a self-selected single smart home device on a 7-point Likert scale (with $1=$ "never" to 7 = "many times per day"). Associated with behavioral components, participants had to answer questions with regard to (a) 
their intention for cross-category use (CC_INT) on a 7-point Likert scale (with $1=$ "totally disagree" to $7=$ "totally agree") and (b) their current cross-category use (CC_USE) by indicating in which of the six defined categories (connectivity, home entertainment, comfort and lighting, security, energy management and smart appliances [14]) they already own and use smart home devices. Cross-category use was defined as the sum of the mentioned categories (ranging from 1 - indicating the use of a smart home device within one category only - to 6 - indicating the use of smart home devices within all defined categories).

\subsection{Assessment of the measurement model}

For the assessment of the measurement model and the path estimations of a model based on smart homerelated antecedents (model 1: figure 1), a model by integrating UTAUT dimensions (model 2: figure 1) and a total (saturated) model (to control direct, indirect and total effects of all variables), we applied a partial least squares (PLS) algorithm by using SmartPLS3 as the underlying toolbox [30].

The PLS algorithm was applied with the path as the weighting scheme and a maximum of 300 iterations (stop criterion $\left(10^{\wedge}-X\right)=7$ ). For the calculation of significance, a bootstrapping approach with 10,000 subsamples (parallel processing) and a bias-corrected and accelerated (BCa) bootstrap as confidence interval method was applied [30].

Regarding the assessment of the measurement model, standard criteria for construct reliability and validity as well as discriminant validity were applied [10]. The outer loadings (standardized factor loadings) showed overall appropriate loadings $>0.7$ (FC4 has to be excluded from further analysis because of a standardized factor loading of .652, <.7). Cronbach's alpha (CA), composite reliability (CR) and average variance extracted (AVE) for all latent (reflective) constructs were acceptable and exceeded the minimum threshold values suggested in the literature $(\mathrm{CA}>0.8, \mathrm{CR}>0.7, \mathrm{AVE}>0.5)[9,10]$. See table 1 for an overview of factor loadings, construct reliability and validity. The bootstrapping procedure showed significance for all of the criteria $(\mathrm{p}<.001)$.

Table 1. Constructs (C), items (I), factor loadings (FL), construct reliability (Cronbach's alpha) and validity (composite reliability; average variance extracted)

\begin{tabular}{lllllll}
\hline $\mathbf{C}$ & I & FL & $\begin{array}{l}\text { Mean } \\
\text { (SD) }\end{array}$ & CA & CR & AVE \\
\hline PE & PE1 & 0.85 & $\begin{array}{l}4.60 \\
(1.38)\end{array}$ & 0.90 & 0.93 & 0.76 \\
& & & & & \\
& PE2 & 0.89 & & & & \\
& PE3 & 0.90 & & & & \\
& PE4 & 0.86 & & & & \\
\hline
\end{tabular}

\begin{tabular}{|c|c|c|c|c|c|c|}
\hline \multirow[t]{4}{*}{$\mathbf{E E}$} & EE1 & 0.90 & $\begin{array}{l}5.10 \\
(1.30)\end{array}$ & 0.94 & 0.96 & 0.85 \\
\hline & EE2 & 0.93 & & & & \\
\hline & EE3 & 0.93 & & & & \\
\hline & EE4 & 0.93 & & & & \\
\hline \multirow[t]{2}{*}{ ENJ } & ENJ1 & 0.94 & $\begin{array}{l}3.92 \\
(1.53)\end{array}$ & 0.71 & 0.86 & 0.76 \\
\hline & ENJ2 & 0.81 & & & & \\
\hline \multirow[t]{3}{*}{ FC } & FC1 & 0.90 & $\begin{array}{l}5.14 \\
(1.37)\end{array}$ & 0.88 & 0.93 & 0.81 \\
\hline & $\mathrm{FC} 2$ & 0.92 & & & & \\
\hline & FC3 & 0.87 & & & & \\
\hline \multirow[t]{3}{*}{ PV } & PV1 & 0.86 & $\begin{array}{l}4.07 \\
(1.30)\end{array}$ & 0.91 & 0.94 & 0.84 \\
\hline & PV2 & 0.95 & & & & \\
\hline & PV3 & 0.94 & & & & \\
\hline \multirow[t]{2}{*}{$\begin{array}{l}\text { DV } \\
P\end{array}$} & DVP1 & 0.82 & $\begin{array}{l}4.60 \\
(1.37)\end{array}$ & 0.71 & 0.87 & 0.77 \\
\hline & DVP2 & 0.93 & & & & \\
\hline \multirow[t]{3}{*}{$\begin{array}{l}\text { CV } \\
P\end{array}$} & CVP1 & 0.90 & $\begin{array}{l}4.81 \\
(1.32)\end{array}$ & 0.85 & 0.91 & 0.77 \\
\hline & CVP2 & 0.92 & & & & \\
\hline & CVP3 & 0.82 & & & & \\
\hline \multirow[t]{4}{*}{ TR } & TR1 & 0.91 & $\begin{array}{l}4.66 \\
(1.18)\end{array}$ & 0.94 & 0.96 & 0.84 \\
\hline & TR2 & 0.93 & & & & \\
\hline & TR3 & 0.91 & & & & \\
\hline & TR4 & 0.91 & & & & \\
\hline HA & HA & 1 & $\begin{array}{l}4.71 \\
(1.52) \\
\end{array}$ & I & I & I \\
\hline $\begin{array}{l}\text { CC_- } \\
\text { INT }\end{array}$ & $\begin{array}{l}\text { CS } \\
\text { INT }\end{array}$ & 1 & $\begin{array}{l}5.09 \\
(1.52)\end{array}$ & I & I & 1 \\
\hline $\begin{array}{l}\mathrm{CC}_{-} \\
\mathrm{USE}\end{array}$ & $\begin{array}{l}\mathrm{CS}_{-} \\
\mathrm{USE}\end{array}$ & 1 & $\begin{array}{l}1.81 \\
(1.14)\end{array}$ & I & I & I \\
\hline
\end{tabular}

Discriminant validity of the latent constructs was examined using the criterion proposed by Fornell and Larcker [9]. As all squared correlations among latent variables are smaller than their AVEs, discriminant validity was given for all the constructs. In addition, applying the heterotrait-monotrait (HTMT) ratio recommended for PLS modeling [10, 11], all constructs showed values $<0.85$ [10], except the ratio between effort expectancy (EE) and facilitating conditions (FC) with a value of 0.87 . However, by comparing the items of the two constructs, it is obvious that they are slightly similar in concept (Construct correlation between EE and FC is .771). and therefore a threshold of $<0.9$ can be applied [10]. According to this, also for the HTMT criteria discriminant validity is given. Bootstrapping $(\mathrm{n}=$ $10,000)$ showed significance for all of the criteria ( $\mathrm{p}<$ $.001)$.

As suggested by Podsakoff et al. [29], potential common method bias was addressed, for instance, by varying scale endpoints and formats, reassuring respondents about the anonymity of their answers and using established measurements. In addition, for the independent constructs we applied a full collinearity 
test suggested for a PLS approach [20, 21]. The full collinearity test showed that all variance inflation factors were smaller than the proposed threshold of 3.3.

\subsection{Main analysis and hypothesis testing}

Both research models - model 1 with selected smart home-relevant antecedents only (H1-H5) and model 2 with the integration of UTAUT dimensions (H6-H7) - showed with regard to cross-category use (CC_USE) that significant effects were only observed for habit (HA) $(\beta=.181($ model 1$) / 0.182($ model 2$), p<0.01)$ and consumer value for personalization (CVP) $(\beta=$ .076 (model 1)/0.074 (model 2), p < 0.05). No significant effects were observed for cross-category intention $\left(C C \_I N T\right)(\beta=.058$ (model 1$) / .059$ (model $2), \mathrm{p}=.127 / .128)$ and trust in smart home companies (TR) $(\beta=.051($ model 1$) / .051$ (model 2$), \mathrm{p}=$ $.181 / .176)$.

With the integration of the specific UTAUT dimensions (model 2), the analysis generated additional information (1) with regard to the prediction of consumers' value for personalization (CVP) by performance and effort expectancy (PE: $\beta=.387$, $\mathrm{p}<$ 0.01 ; EE: $\beta=.244, p<0.01)$; (2) with regard to the concrete roles of habit (HA) and consumers' value for personalization (CVP) in predicting cross-category use (CC_USE); and (3) with regard to an increase of explained variance especially for cross-category intention $\left(\mathrm{R}^{2}=.248\right.$, model 1 , to $\mathrm{R}^{2}=.480$, model 2$)$ and consumers' value for personalization $\left(\mathrm{R}^{2}=.346\right.$, model 1 , to $\mathrm{R}^{2}=.524$, model 2 ).

See table 2 for an overview of PLS-SEM (structural equation modeling) results for the two hypothesized models and the total (saturated) model. Fit indices are reported, but current research is considered with regard to a careful use and interpretation of those fit indices (i.e., standardized root mean square residual, SRMR; normed fit index, NFI) using a PLS approach [10].

Table 2. Results of PLS-SEM

\begin{tabular}{|c|c|c|c|}
\hline \multicolumn{4}{|c|}{$\begin{array}{l}\text { Model 1: Spot Model on Smart Home-Relevant } \\
\text { Antecedents }\end{array}$} \\
\hline $\begin{array}{l}D V: \\
C C_{I} I N T \\
\left(\mathrm{R}^{2}=\right. \\
\left..248^{* *}\right)\end{array}$ & Beta & $\begin{array}{l}\boldsymbol{D} \boldsymbol{V}: \\
\boldsymbol{C V P} \\
\left(\mathrm{R}^{2}=.346^{* *}\right)\end{array}$ & Beta \\
\hline$H A$ & $.497 * *$ & $H A$ & $.142 * *$ \\
\hline \multirow[t]{2}{*}{$D V P$} & .015 & $D V P$ & $.091 * *$ \\
\hline & & CC_INT & $.494 * *$ \\
\hline $\begin{array}{l}\text { DV: } \\
\text { TR } \\
\left(\mathrm{R}^{2}=.276\right)\end{array}$ & Beta & $\begin{array}{l}\text { DV: } \\
\text { CC_USE } \\
\left(\mathrm{R}^{2}=.083\right)\end{array}$ & \\
\hline HA & $.079 * *$ & HA & $.181 * *$ \\
\hline DVP & $.062 * *$ & CC_INT & .058 \\
\hline
\end{tabular}

\begin{tabular}{|c|c|c|c|}
\hline CC_INT & $.265^{* *}$ & CVP & $.076 *$ \\
\hline CVP & $.268 * *$ & TR & .051 \\
\hline \multicolumn{4}{|c|}{$\begin{array}{l}\text { Goodness of Fit: } \\
\text { SRMR }=.042 ; \mathrm{CHI}^{2}=710.28 ; \mathrm{NFI}=0.895\end{array}$} \\
\hline \multicolumn{4}{|c|}{ Model 2: Model Including UTAUT Dimensions } \\
\hline $\begin{array}{l}D V: \\
C C \_I N T \\
\left(\mathrm{R}^{2}=\right. \\
.480 * *)\end{array}$ & Beta & $\begin{array}{l}\boldsymbol{D V}: \\
\boldsymbol{C V P} \\
\left(\mathrm{R}^{2}=.524 * *\right)\end{array}$ & Beta \\
\hline $\mathrm{PE}$ & $.318^{* *}$ & $\mathrm{PE}$ & $.387 * *$ \\
\hline $\mathrm{EE}$ & $.120 * *$ & $\mathrm{EE}$ & $.244 * *$ \\
\hline ENJ & .001 & HA & .048 \\
\hline $\mathrm{FC}$ & $.124 * *$ & DVP & .041 \\
\hline PV & $.107 * *$ & CC_INT & $.181 * *$ \\
\hline HA & $.235^{* *}$ & & \\
\hline DVP & -.04 & & \\
\hline $\begin{array}{l}\text { DV: } \\
\text { TR } \\
\left(\mathrm{R}^{2}=\right. \\
.277 * *)\end{array}$ & Beta & $\begin{array}{l}\text { DV: } \\
\text { CC_USE }\left(\mathrm{R}^{2}\right. \\
\left.=.083^{*} *\right)\end{array}$ & Beta \\
\hline HA & $.079 *$ & HA & $.182 * *$ \\
\hline DVP & $.062 *$ & CC_INT & .059 \\
\hline CC_INT & $.264 * *$ & CVP & $.074 *$ \\
\hline CVP & $.270 * *$ & TR & .051 \\
\hline \multicolumn{4}{|c|}{$\begin{array}{l}\text { Goodness of Fit: } \\
\text { SRMR }=.059 ; \mathrm{CHI}^{2}=2844.69 ; \mathrm{NFI}=.868\end{array}$} \\
\hline \multicolumn{4}{|c|}{ Model 3: Total (Saturated) Model } \\
\hline $\begin{array}{l}\text { DV: } \\
\text { CC_INT } \\
\left(\mathrm{R}^{2}=.480\right)\end{array}$ & Beta & $\begin{array}{l}\text { DV: } \\
\text { CVP } \\
\left(\mathrm{R}^{2}=.548\right) \\
\end{array}$ & Beta \\
\hline $\mathrm{PE}$ & $.318 * *$ & $\mathrm{PE}$ & $.322 * *$ \\
\hline $\mathrm{EE}$ & $.120 * *$ & $\mathrm{EE}$ & $.124 * *$ \\
\hline ENJ & -.003 & ENJ & $.099 * *$ \\
\hline FC & $.125 * *$ & $\mathrm{FC}$ & $.159 * *$ \\
\hline PV & $.108 * *$ & PV & $.087 * *$ \\
\hline HA & $.236 * *$ & HA & .010 \\
\hline DVP & -.040 & $\begin{array}{l}\text { DVP } \\
\text { CC_INT }\end{array}$ & $\begin{array}{l}.034 \\
.154 * *\end{array}$ \\
\hline $\begin{array}{l}\text { DV: } \\
\text { TR } \\
\left(\mathrm{R}^{2}=.332\right) \\
\end{array}$ & Beta & $\begin{array}{l}\text { DV: } \\
\text { CC_USE } \\
\left(\mathrm{R}^{2}=.096\right) \\
\end{array}$ & Beta \\
\hline $\mathrm{PE}$ & $.111 * *$ & $\mathrm{PE}$ & -.018 \\
\hline $\mathrm{EE}$ & .055 & $\mathrm{EE}$ & $-.109 *$ \\
\hline ENJ & $.080 *$ & ENJ & .060 \\
\hline $\mathrm{FC}$ & -.031 & $\mathrm{FC}$ & -.004 \\
\hline PV & $.206 * *$ & PV & .069 \\
\hline HA & .027 & HA & $.179 * *$ \\
\hline DVP & .036 & DVP & -.007 \\
\hline CC_INT & .180 & CC_INT & .079 \\
\hline CVP & $.131 * *$ & CVP & $.096^{*}$ \\
\hline & & TR & .036 \\
\hline
\end{tabular}

Goodness of Fit:

$\mathrm{SRMR}=.046 ; \mathrm{CHI}^{2}=2772.44 ; \mathrm{NFI}=0.871$

Note: ${ }^{*} p<.05 ; * * p<.01$ (two-tailed test)

With regard to the hypothesized mediation effect of CVP and TR, we chose the simplified model (model 1) for an in-depth analysis. We followed the procedure proposed by Hair et al. [10] to identify different types of mediation effects. We reported the values for the variance accounted for (VAF) accordingly. 
First, the PLS-SEM analysis showed a significant partial mediation effect of consumers' value for personalization (CVP) with regard to (1) the positive relation between cross-category intention (CC_INT) and cross-category use (CC_USE) $(\beta=.037, \mathrm{p}<.05)$ and (2) as part of a sequential mediation between the relationship of habit (HA) on cross-category intention (CC_INT) and cross-category use (CC_USE) $(\beta=$ $.019, \mathrm{p}<.05 ; \mathrm{VAF}=50 \%$ (with a total effect of $\beta=$ .116)). This partial mediation through CVP still holds true in model $2(\mathrm{VAF}=33 \%)[10]$.

Second, no significant mediation effect of trust was found for the mediation of the relation between crosscategory intention (CC_INT) and cross-category use (CC_USE) $(\beta=.013, p=.189)$ and between consumers' perceived value for personalization (CVP) and cross-category use (CC_USE) $(\beta=.014, \mathrm{p}=.191)$.

\section{Discussion}

Based on an online survey of users in three European countries and partial least squares structural equation modeling, this paper extends aspects of technology acceptance and use $[13,35]$ by integrating perceived value from personalization, trust in smart home companies and privacy components. The underlying framework was that in the smart home ecosystem consumers' use and acceptance of smart devices are not related to a single product, service or application, but instead to an entire smart home ecosystem [13]. This research takes into account the complexity of a smart home ecosystem as a multifaceted assemblage of connected smart technologies across different segments [28] (see figure 2 for an overview of the results).

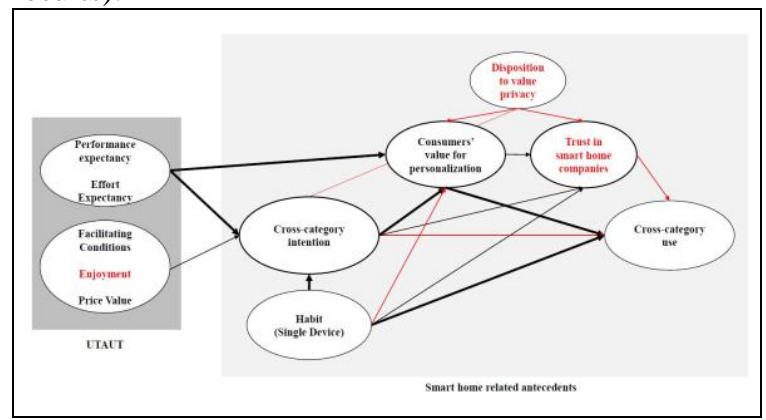

Figure 2. Overview of results

With regard to the behavioral component of current cross-category use, habit (HA, H5b) and consumers' perceived value of personalization (CVP, $\mathrm{H} 2$ ) are significant predictors. However, the intention of cross-category use (CC_INT, H1) and trust in companies (TR) are not directly related to current cross-category use (H3).

Habit plays an important role, since the increased frequency of use of a single smart device predicts the cross-category use of smart devices. As already shown by Kim and Malhotra [17], habit in the form of prior use is a strong antecedent of future technology use. However, more recent literature has challenged this simple relation and has called for the investigation of mediating constructs [35]. Our analysis does indeed show that, in a complex smart home ecosystem, habit is not a direct predictor of future usage. In fact, our findings indicate the central role of consumers' perceived value for personalization [6] within a smart home ecosystem.

With regard to consumers' value for personalization, the analysis showed that if people perceive the performance (PE, H7a) of a smart home ecosystem as sufficient and the effort (EE, H7b) they have to invest in order to set up a smart home ecosystem as appropriate (UTAUT), they have an increased perception of the value for personalization [6]. This result indicates that the value perception of personalization could be associated with (1) the understanding of the underlying assemblage of a smart home ecosystem; (2) the knowledge about the necessity of multiple and connected smart devices; and (3) the knowledge about the necessity of data collection and analysis in order to increase the personalization of devices and applications, which in consequence will increase users' well-being [14].

Furthermore, the results also showed the importance of consumers' perceived value for personalization by partially mediating the relationship between intention of cross-category use and current cross-category use (H2). This again indicates that an assemblage of different smart devices and the intention of cross-category use is mainly dependent on the potential of personalized services and applications and the perceived value for the users themselves, which in consequence leads to the appropriate behavior - the establishment of a smart home ecosystem.

With regard to the relationship between the use habit of a single smart home device and consumers' perceived value for personalization, the direct link is not significant in model 2 versus model 1 (H5c), but the results showed a sequential mediation from habit to intention of cross-category use to consumers' perceived value for personalization, which finally also affects cross-category use. A user's appreciation of a single smart device does not predict the necessity of personalized services and applications. Only the appreciation of a smart home ecosystem as an assemblage of multiple smart devices and existing habits leads to the perception of value generation through personalization. This result is interesting, because it confirms that, for the user, the ecosystem is more important than the single component. For 
companies producing components, this is an important message: the device is important, but they need to choose carefully how to position themselves in the different (maybe competing) ecosystems.

With regard to the role of trust in smart home companies, the analysis showed that trust (TR) is positively predicted by habit (HA, H5d), consumers' cross-category intention (CC_INT) and consumers' perceived value for personalization (CVP). Especially consumers' value for personalization and the intention of cross-category use are the main predictors, which are associated with the knowledge of a necessity of products from different companies and data transfer to different companies [14, 28]. Therefore, with an increase in intention as well as in consumers' need for personalization, trust in smart home companies is increasing as well. However, trust in smart home companies seems to be affected by the overall positive attitude and acceptance of consumers towards a smart home ecosystem, but trust has no direct effect on current cross-category use (CC_USE, H3). Therefore, trust in smart home companies cannot be seen as a significant mediator driving use behavior, but more as an accompanying side effect. These results may be true for components that feature a decent level of trustworthiness. It may be that if users have a wellestablished trust level in smart home companies, then trust is not an important antecedent of cross-category use. However, this counterintuitive result calls for further research to establish a "hygienic" level of trust that device manufacturers have to respect in order to sell at all.

Compared to trust in companies, similar results were observed for consumers' disposition to value privacy. Although privacy issues and privacy concerns are often mentioned as potential inhibiting factors regarding the use of (smart) technologies [1, 15], the data analysis could not confirm this assumption. Neither did we observe a negative effect of consumers' disposition to value privacy (DVP) on consumers' intention of cross-category use (CC_INT, $\mathrm{H} 4 \mathrm{a}$ ), nor on consumers' perceived value for personalization (CVP, H4b). However, research with regard to the privacy paradox offers some suggestions for the interpretation of our results [1, 27]. The counterintuitive positive relation between consumers' disposition to value privacy and trust in companies might be related to ignorance [38] or the development of privacy-enhancing technologies during the last few years [26]. While technologies to protect privacy have become the standard, hence boosting trust, it is only in recent times that the problems caused by behavioral surplus [38] are becoming common knowledge. Hence, while the participants in the present study may exhibit the trust profile evidenced in this paper, a future study should retest this construct to account for more widespread knowledge of the pernicious effect of companies using and abusing behavioral surplus.

With regard to the behavioral component of the intention for cross-category use of a smart home ecosystem, the results of the present study show that the selected UTAUT dimensions - namely, performance expectancy (PE), effort expectancy (EE), facilitating conditions (FC), price value (PV) and habit (HA) - are positively related (H5a; H6). Performance expectancy and habit are the strongest predictors of intention for cross-segment use, while effort expectancy, facilitating conditions and price value seem to play a minor role in cross-segment usage behavior. These results are mainly in line with existing research [35] indicating the importance of (1) consumers' expectation of the kind of value the use of a technology offers (e.g., increased convenience or performance, makes life easier, saves time, etc.) [18, 35 ] and (2) the ongoing use (use habit) of a technology or device itself [35]. Especially within a smart home ecosystem, the expectation with regard to the performance of the whole assemblage as well as the spillover effect from current experiences using a single smart home device are crucial drivers of smart home ecosystem acceptance [17, 18, 24]. While effort expectancy, facilitating conditions and price value possibly act as convenience factors in order to set up a smart home ecosystem, enjoyment has no significant role in this setup (H6c). However, existing research often sees facilitation conditions as well as enjoyment as important antecedents $[4,35]$. Thus, the effect of facilitating conditions might indicate that users believe in their abilities and knowledge using more than one device. In line with users' post-adoption behavior [23], we assume that it is just a small step from a single device to a multi-device user. Hence, the facilitating conditions play a minor role in this context. With regard to the insignificant effect of enjoyment, the reason might be that the complex assemblage of a smart home ecosystem, which consists of a bundle of utilitarian (e.g., security, light) and hedonic (e.g., smart speakers) components, is mainly performance driven. Enjoyment is more strongly related to specific single technologies [4], which could also hold true in a smart home environment, but seems to have a minor role for the acceptance and use of the whole smart home ecosystem.

In summary, the project investigated smart technology-relevant antecedents - CVP, DVP, TR and $\mathrm{HA}$ - to explain technology acceptance and use across device segments. Furthermore, it used selected UTAUT dimensions - PE, EE, ENJ, FC and PV. While the UTAUT dimensions are mainly responsible for explaining the intention of cross-category use, 
habit and especially consumers' value for personalization were the main drivers as well as an important mediator (CVP) for the prediction of current cross-category use. Consumers use and are willing to use smart devices and services in order to establish a smart home ecosystem, but only if they perceive it as providing additional value - with personalization as the main driver. Trust in companies only plays a minor role and seems to be already established within a sample of owners and users. Consumers' disposition to value privacy has no effect at all.

\section{Conclusion, Limitations and Further Research}

As already mentioned, the assemblage and the complexity of a smart home ecosystem make it necessary to extend traditional technology acceptance models. Our findings underline this assumption. For instance, we were able to show the importance of new mediators such as consumers' perceived value for personalization. The relevance of personalization and customization through technologies was already demonstrated in 2000, but today it is even more relevant [3]. Even though the context of the study was different, our findings underline the high relevance of personalization.

Despite these insights into specific smart homeoriented mediators in a smart home ecosystem, the study has some limitations that should be addressed in future research. First, we suggest the combination of actual usage behavior with smart home devices and survey data. Based on observational studies, further research could shed light on user-smart home interaction [13]. Second, we focused on important mediating effects, but further research should also analyze potential moderating effects. For instance, the moderating impact of different user types could be interesting. Especially a differentiation between users such as initial, short-term and long-term users [23] could be a contribution in this research area. Further, a comparison of single users with cross-segment users could be valuable. Third, future research should also address the impact of the first application used in the smart home context. Which application is the initial trigger for entering the smart home ecosystem? At least in the context of smart home technologies, "the whole is greater than the sum of its parts." That means that value increases by connecting smart devices to a smart home ecosystem. Further research should take this enhanced value for customers also into account.

\section{References}

[1] Awad, N.F., and M.S. Krishnan, "The personalization privacy paradox: an empirical evaluation of information transparency and the willingness to be profiled online for personalization", MIS quarterly, 2006, pp. 13-28.

[2] Benbasat, I., and H. Barki, "Quo vadis, TAM?", Journal of the AIS (8:4), 2007, pp. 212-218.

[3] Bitner, M.J., S.W. Brown, and M.L. Meuter, "Technology infusion in service encounters", Journal of the Academy of Marketing Science (28:1), 2000, pp. 138-149.

[4] Brown, S.A., and V. Venkatesh "Model of adoption of "Technology in the household: A baseline model test and extension incorporating household life cycle", MIS Quarterly (29:4), 2005, pp. 399-426.

[5] Chaudhuri, A., and M.B. Holbrook, "The chain of effects from brand trust and brand affect to brand performance: the role of brand loyalty", Journal of Marketing (65:2), 2001, pp. 81-93.

[6] Chellappa, R.K., \& R.G. Sin, "Personalization versus privacy: An empirical examination of the online consumer's dilemma", Information technology and management (6:23), 2005, pp. 181-202.

[7] Constantiou, I.D., C. Lehrer, and T. Hess, "Changing information retrieval behaviours: an empirical investigation of users' cognitive processes in the choice of location-based services", European Journal of Information Systems (23:5), 2014, pp. 513-528.

[8] Davis, F.D., R.P. Bagozzi, and P.R. Warshaw, P, "User acceptance of computer technology: a comparison of two theoretical models", Management Science (35:8), 1989, pp. 982-1003.

[9] Fornell, C., and D.F. Larcker, "Evaluating structural equation models with unobservable variables and measurement error", Journal of Marketing Research 18, 1981, pp. 39-50.

[10] Hair, J. F., G.T.M., Hult, C.M. Ringle, and M. Sarstedt, "A Primer on Partial Least Squares Structural Equation Modeling (PLS-SEM)”, 2nd Ed., Sage: Thousand Oaks, 2017.

[11] Hair, J.F., M. Sarstedt, and C.M. Ringle, "Rethinking some of the rethinking of partial least squares", European Journal of Marketing, 2019.

[12] Hubert, M., M. Blut, C. Brock, C. Backhaus, and T. Eberhardt, "Acceptance of smartphone-based mobile shopping: Mobile benefits, customer characteristics, perceived risks, and the impact of application context", Psychology \& Marketing (34:2), 2017, pp. 175-194.

[13] Hubert, M., M. Blut, C. Brock, R.W. Zhang, V. Koch, and R. Riedl, "The influence of acceptance and adoption 
drivers on smart home usage", European Journal of Marketing, 2018.

[14] Huhn, P. "Statista Digital Market Outlook", Statista, 2017, ww.statista.com.

[15] Jacobsson, A., M. Boldt, and B. Carlsson, "A risk analysis of a smart home automation system", Future Generation Computer Systems 56, 2016, pp. 719-733.

[16] Karjaluoto, H., Jayawardhena, C., Leppäniemi, M., \& Pihlström, M. (2012). How value and trust influence loyalty in wireless telecommunications industry. Telecommunications Policy, 36(8), 636-649.

[17] Kim, S.S., and N.K. Malhotra, "A longitudinal model of continued IS use: An integrative view of four mechanisms underlying postadoption phenomena", Management Science (51:5), 2005, pp. 741-755.

[18] Kim, S.S., N.K. Malhotra, and S. Narasimhan, "Two competing perspectives on automatic use: A theoretical and empirical comparison", Information Systems Research (16:4), 2005, pp. 418-432.

[19] King, W.R., and J. He "A meta-analysis of the technology acceptance model", Information \& management (43:6), 2006, pp. 740-755.

[20] Kock, N. "Common method bias in PLS-SEM: A full collinearity assessment approach", International Journal of e-Collaboration (IJeC), 11(4), 2015, pp. 1-10.

[21] Kock, N., and G.S. Lynn, "Lateral collinearity and misleading results in variance-based SEM: An illustration and recommendations", Journal of the Association for Information Systems (13:7), 2012, pp. 546-580.

[22] Li, Y. "The impact of disposition to privacy, website reputation and website familiarity on information privacy concerns", Decision support systems, 57, 2014, pp. 343-354.

[23] Liao, C., P. Palvia, and J.L. Chen, "Information technology adoption behavior life cycle: Toward a technology continuance theory (TCT)", International Journal of Information Management (29:4), 2009, pp. 309 320.

[24] Limayem, M., S.G. Hirt, and C.M.K. Cheung, "How habit limits the predictive power of intentions: The case of IS continuance", MIS Quarterly (31:4), 2007, pp. 705-737.

[25] Lutz, C., C.P. Hoffmann, E. Bucher, and C. Fieseler, „The role of privacy concerns in the sharing economy. Information", Communication \& Society (21:10), 2018, pp. 1472-1492.

[26] Maple, C., "Security and privacy in the internet of things", Journal of Cyber Policy (2:2), 2017, pp. 155-184.
[27] Norberg, P.A., D.R. Horne, and D.A. Horne, "The privacy paradox: Personal information disclosure intentions versus behaviors", Journal of consumer affairs, 41(1), 2007, pp. 100-126.

[28] Novak, T.P., and D.L. Hoffman, "Relationship journeys in the internet of things: a new framework for understanding interactions between consumers and smart objects", Journal of the Academy of Marketing Science (47:2), 2019, pp. 216237.

[29] Podsakoff, P.M., S.B. MacKenzie, J.Y. Lee, and N.P. Podsakoff, "Common method biases in behavioral research: a critical review of the literature and recommended remedies", Journal of Applied Psychology (88:5), 2003, pp. 879-903.

[30] Ringle, C.M., S. Wende, and J.-M. Becker, "SmartPLS 3." Boenningstedt: SmartPLS GmbH, 2015, http://www.smartpls.com.

[31] Slade, E.L., Y.K. Dwivedi, N.C. Piercy, and M.D. Williams, "Modeling consumers' adoption intentions of remote mobile payments in the United Kingdom: extending UTAUT with innovativeness, risk, and trust", Psychology \& Marketing (32:8), 2015, pp. 860-873.

[32] Statista, 2019, https://www.statista.com/statistics/471264/iot-number-ofconnected-devices-worldwide/.

[33] Venkatesh, V., and F.D. Davis, "A theoretical extension of the technology acceptance model: Four longitudinal field studies", Management Science (46:2), 2000, pp. 186-204.

[34] Venkatesh, V., F.D. Davis, and M.G. Morris, "Dead or alive? The development, trajectory and future of technology adoption research," Journal of the AIS (8:4), 2007, pp. 268286.

[35] Venkatesh, V., J.Y. Thong, and X. Xu, "Consumer acceptance and use of information technology: extending the unified theory of acceptance and use of technology. MIS quarterly (36:1), 2012, pp. 157-178.

[36] Xu, H., T. Dinev, H.J. Smith, and P. Hart, "Information privacy concerns: Linking individual perceptions with institutional privacy assurances", Journal of the Association for Information Systems (12:12), 2011, 1.

[37] Yang, H., H. Lee, and H. Zo, "User acceptance of smart home services: an extension of the theory of planned behavior", Industrial Management and Data Systems (117:1), 2017, pp. 68-89.

[38] Zuboff, S., "The age of surveillance capitalism: the fight for the future at the new frontier of power", Profile Books, 2019. 